Eastern Illinois University

The Keep

Faculty Research \& Creative Activity

Biological Sciences

January 2007

\title{
Production of methanethiol and volatile sulfur compounds by the archaeon "Ferroplasma acidarmanus"
}

David J. Baumler

University of Wisconsin, Madison

Kai F. Hung

Eastern Illinois University, khung@eiu.edu

Kwang Cheol Jeong

University of Wisconsin, Madison

Charles W. Kaspar

University of Wisconsin, Madison

Follow this and additional works at: http://thekeep.eiu.edu/bio_fac

Part of the Biology Commons

\section{Recommended Citation}

Baumler, David J.; Hung, Kai F.; Jeong, Kwang Cheol; and Kaspar, Charles W., "Production of methanethiol and volatile sulfur compounds by the archaeon "Ferroplasma acidarmanus"" (2007). Faculty Research \& Creative Activity. 201.

http://thekeep.eiu.edu/bio_fac/201 


\title{
Production of methanethiol and volatile sulfur compounds by the archaeon "Ferroplasma acidarmanus"
}

\author{
David J. Baumler, Kai-Foong Hung, Kwang Cheol Jeong, and Charles W. Kaspar
}

\begin{abstract}
Acidophiles are typically isolated from sulfaterich ecological niches yet the role of sulfur metabolism in their growth and survival is poorly defined. Studies of heterotrophically grown "Ferroplasma acidarmanus" showed that its growth requires a minimum of 100 $\mathrm{mM}$ of a sulfate-containing salt. Headspace gas analyses by GC/ MS determined that the volatile sulfur compound emitted by active "F. acidarmanus" cultures is methanethiol. In "F. acidarmanus" cultures grown either heterotrophically or chemolithotrophically, methanethiol was produced constitutively. Radiotracer studies with 35S-labeled methionine, cysteine, and sulfate showed that all three were used in methanethiol production. Additionally, $3 \mathrm{H}$-labeled methionine was incorporated into methanethiol and was probably used as a methyl-group donor. Methanethiol production in whole cell lysates supplied with SO3 2- indicated that NADPH-dependant sulfite reductase and methyltransferase activities were present. Cell lysates also contained enzymatic activity for methionine-c-lyase that cleaved the side chain of either methionine to form methanethiol or cysteine to produce H2S. Since methanethiol was detected from the degradation of cysteine, it is likely that sulfide was methylated by a thiol methyltransferase. Collectively, these data demonstrate that "F. acidarmanus" produces methanethiol through the metabolism of methionine, cysteine, or sulfate. This is the first report of a methanethiol-producing acidophile, thus identifying a new contributor to the global sulfur cycle.
\end{abstract}

Keywords: Cysteine, Methanethiol, Methionine, Sulfate, Sulfite reductase, Thiol methyltransferase
Abbreviations
APS Adenosine 50-phosphosulfate reductase
CGS Cystathionine-c-synthase
CPB Citrate phosphate buffer
dH2O Deionized water
DMDS Dimethyldisulfide
Dsr Dissimilatory sulfite reductase
DTT Dithiolthreitol
GC Gas chromatography
mfer Chemolithotrophic growth medium
for "Ferroplasma acidarmanus" strain fer1
LSC Liquid scintillation counting
MGL Methionine-c-lyase
MPN Most probable number
MT Methanethiol
NoS No sulfate growth medium $(6 \mathrm{~N} \mathrm{HCl}$ was used as
acidulant and the only source of sulfate was from 
added $\mathrm{Na} 2 \mathrm{SO} 4$ or $\mathrm{MgSO} 4$ )

ORFs Open reading frames

PAPS Phosphoadenosine 50-phosphosulfate reductase

PFPD Pulsed flame photometric detector

PLP Pyridoxal 50-phosphate hydrate

PTFE Polytetrafluoroethylene

SAM S-adenosyl-L-methionine

TCA Trichloroacetic acid

TMT Thiol methyltransferase

VOSC Volatile organic sulfur compound

VSC Volatile sulfur compound

\section{Introduction}

Sulfur is one of the more common elements in the biosphere that is essential to life. It is present in the amino acids cysteine and methionine, some vitamins, enzymes, and coenzymes. Furthermore, sulfide is essential to iron-sulfur ( $\mathrm{Fe}-\mathrm{S})$ clusters that are present in metalloproteins, like ferrodoxin and cytochrome C. Sulfate (SO4 2-), the most oxidized form of sulfur, is utilized as a sulfur source by plants, fungi, and prokaryotes through the assimilatory sulfate reduction pathway. In comparison, sulfate-reducing bacteria generate energy from the reduction of sulfate to $\mathrm{H} 2 \mathrm{~S}$ by the dissimilatory sulfate reduction pathway while other prokaryotes can utilize reduced forms of sulfur as an energy source. Dissimilatory sulfate-reducing microorganisms have a high demand for sulfate, with freshwater bacteria requiring SO4 2- levels ranging from 100-250 $\mathrm{lM}$, and marine microorganisms needing $* 25 \mathrm{mM}$ (Nealson 1997). Although not typically mentioned, acidic biotopes have the highest sulfate concentrations on Earth yet the metabolism and production of sulfur compounds by organisms inhabiting these sites have not been thoroughly investigated.

The Richmond mine in Iron Mountain, CA contains acidic waters with some of the lowest $\mathrm{pH}(-3.7)$ values ever reported (Nordstrom and Alpers 1999). The acidic waters of the Richmond mine have reported sulfate concentrations ranging from $657-786 \mathrm{mM}$ (Druschel et al. 2004). This site has been the subject of recent research that resulted in the isolation of unique archaeal, bacterial, and eukaryotic organisms (Edwards et al. 2000; Tyson et al. 2005; Baker et al. 2003; Baker et al. 2004). Archaea are of particular interest because of their relatively recent description and placement in a separate phylogenetic domain. Many archaea are extremophiles but others are found in an array of environments including the ocean where they have been found in high numbers (Giovannoni and Stingl 2005). Due to their presence in extreme environments and unidentified nutritional requirements, basic molecular tools and culture methods are lacking for many archaeal species, which has hampered progress on the studies of these organisms. Of the isolates from the Richmond mine, the archaeon "F. acidarmanus" stands out as an attractive candidate for the study of sulfur metabolism because it has an unusually high ( $\$ 100 \mathrm{mM}$ ) sulfate requirement for growth (Baumler et al. 2005), and its genome $(* 1.94 \mathrm{Mb})$ has been sequenced (Allen et al. 2007). A metabolic reconstruction of a " $\mathrm{F}$. acidarmanus" cell model based on genome annotation predicts that SO4 2-is transported into the cytoplasm but its role in metabolism is unknown (Allen et al. 2007). 
Additionally, Ferrer et al. (2007) revealed that F. acidiphilum has metabolic machinery that is dominated by iron-containing proteins, many with $\mathrm{Fe}-\mathrm{S}$ centers, that adds to the body of information on the importance of sulfur and sulfur metabolism in Ferroplasma species and the appropriateness of studying sulfur metabolism in " $F$. acidarmanus".

Initial studies on the production of volatile sulfur gases by "F. acidarmanus" were conducted because of the foul odor associated with cultures. The headspace gases were directed into a zinc acetate trap where a white precipitate formed. Analysis of the precipitate for sulfide by the formation of methylene blue (Cline 1969) was negative but ion coupled plasma-optical emission spectroscopy detected the presence of zinc and sulfur (Baumler et al. 2005). This was the first report of the production of a volatile sulfur compound (VSC) by a Ferroplasma spp. In the current study the VSC produced by " $\mathrm{F}$. acidarmanus" was identified as the volatile organic sulfur compound (VOSC) methanethiol (MT). Dimethyldisulfide (DMDS) was also detected and is likely the dimerized form of MT that is produced in the presence of oxygen (Lomans et al. 2002; Nordmann et al. 1994). 35S- and 3H-labeled substrates (methionine, cysteine, and sulfate) as well as enzyme assays with cell lysates were used to determine precursors and probable intermediates involved in the MT production pathway. Since VOSCs surpass $\mathrm{H} 2 \mathrm{~S}$ as the major biogenic sulfur carriers to the atmosphere (Kelly et al. 1994; Kiene 1996), this study identified a new contributor to the biogeochemical cycling of sulfur in one of the most sulfur-rich ecological niches on Earth.

\section{Materials and methods}

Strains and growth conditions

Archaeoglobus fulgidus-ATCC 49558 was grown anaerobically in 1775 Archaeoglobus medium (DSM 399) with dithiolthreitol (Sigma, St. Louis, MO) used as reductant. " $F$. acidarmanus" strain fer1 was grown in either chemolithotrophic mfer medium (Baumler et al. 2005) or in a newly defined medium termed NoS (No Sulfate, $6 \mathrm{~N} \mathrm{HCl}$ was used as acidulant and the only source of sulfate was from added $\mathrm{Na} 2 \mathrm{SO} 4$ or MgSO4). Freshly prepared mfer was inoculated as described (Baumler et al. 2005), while NoS medium was inoculated with a 14-day culture of "F. acidarmanus" grown in NoS. All growth studies were conducted with static cultures $[10 \%(\mathrm{v} / \mathrm{v})]$ at 37 C. Growth measurements were determined spectrophotometrically (OD492), and viable cell counts were determined using a most probable number (MPN) technique in mfer medium as previously described (Baumler et al. 2005).

\section{Media composition and preparation}

For chemolithotrophic growth studies, mfer medium was prepared as previously described (Baumler et al. 2005). For heterotrophic growth, NoS medium was comprised of the following per liter: $\mathrm{Na} 2 \mathrm{SO} 4,350 \mathrm{mM}$; $\mathrm{NH} 4 \mathrm{Cl}, 10 \mathrm{mM}$; $\mathrm{NiCl}$, $2 \mathrm{mM}$; KH2PO4, $3 \mathrm{mM}$; $\mathrm{MgCl} 2,0.65 \mathrm{mM}$; MnCl2, $0.05 \mathrm{mM}$; ZnCl2, $0.51 \mathrm{mM}$; $\mathrm{CoCl} 2,0.04 \mathrm{mM}$; H3BO3, $0.5 \mathrm{mM}$; Na2MoO4, $0.35 \mathrm{mM}$; and $0.1 \%$ (w/v) yeast extract 
(Becton Dickinson, Sparks, MD). Chemicals were obtained from Sigma/Aldrich chemical company except KH2PO4 (Mallinckrodt Inc., Hazelwood, MO), and H3BO3 (EM Science, Gibbstown, NJ).

NoS medium was adjusted to $\mathrm{pH} 1.0$ using concentrated $\mathrm{HCl}(6 \mathrm{~N})$, and prepared by adding ingredients to deionized water ( $\mathrm{dH} 2 \mathrm{O})$, except $\mathrm{Na} 2 \mathrm{SO} 4$ and yeast extract, and adjusted to a final volume of 11 with $\mathrm{dH} 2 \mathrm{O}$ (basal salts). The basal salts solution and yeast extract concentrate $(10 \% \mathrm{w} / \mathrm{v})$ were sterilized at $121 \mathrm{C}$ for $25 \mathrm{~min}$ at $17 \mathrm{psi}$. To eliminate precipitate that results from the acidification of yeast extract, Na2SO4 was added to the yeast extract solution $(10 \mathrm{ml})$, adjusted to the appropriate $\mathrm{pH}$, then added to $190 \mathrm{ml}$ of the autoclaved basal salts solution, and filtered through a $0.2-1 \mathrm{~m}$ pore membrane filter (Fisher). This filtered yeast extract and Na2SO4 solution (200 ml) was added to $800 \mathrm{ml}$ of sterile basal salts solutions to make the completed NoS medium. All $\mathrm{pH}$ measurements were made as previously described (Macalady et al. 2004).

Headspace analysis by gas chromatography/mass spectroscopy

Headspace gas (250 11) was sampled from either A. fulgidus (3 days) or " $\mathrm{F}$. acidarmanus" ( 7 or 14 days) cultures grown in mfer in $125 \mathrm{ml}$ headspace vials (Wheaton, Millville, NJ) with a gas-tight syringe (Hamilton Company, Reno, NV) and analyzed by GC/MS (Hewlett Packard 6890 gas chromatograph connected to an Agilent 5973 network mass detector). The instrument was under the control of Chemstation software, and analyses conducted in selected ion monitoring mode programmed for all known biotically produced VOSCs (Lomans et al. 2002). A Supelco Supel-Q Plot column (30 m - $0.32 \mathrm{~mm}$ ) was used and running conditions were $50 \mathrm{C}(1 \mathrm{~min})$ to $230 \mathrm{C}$ at a rate of $10 \mathrm{C} / \mathrm{min}$. The injector temperature was $250 \mathrm{C}$. Helium was used as a carrier gas at a flow rate of $3 \mathrm{ml} / \mathrm{min}$. The mass spectrometer operated in the electron ionization mode $(70 \mathrm{eV})$ at a source temperature of $250 \mathrm{C}$.

Gas chromatography, pulsed flame photometric detection of MT

Headspace gas (250 11) from cultures was extracted using a gas-tight syringe and analyzed using a GC-PFPD (Varian, Walnut Creek, CA). A CP8510 fused silica capillary column $(15 \mathrm{~m} \cdot 0.25 \mathrm{~mm}, 1.0 \mathrm{~lm}$ film, Varian $)$ was used with the following running conditions: $50 \mathrm{C}(1 \mathrm{~min})$ to $230 \mathrm{C}$ at a rate of $10 \mathrm{C} / \mathrm{min}$. The injector was operated in a splitless mode with a temperature of $250 \mathrm{C}$. Helium was used as the carrier gas at a flow rate of $3 \mathrm{ml} / \mathrm{min}$. The pulsed flame photometric detector (PFPD) was held at $240 \mathrm{C}$ with the following flow rates: air 1 at $18 \mathrm{ml} / \mathrm{min}$ and $\mathrm{H} 2$ at $14 \mathrm{ml} / \mathrm{min}$, and air 2 at 10 $\mathrm{ml} / \mathrm{min}$. Detector response signals were integrated using computer software (Star Workstation 6.2, Varian). MT and DMDS were quantified by comparison to gas standards (Sigma). A standard curve was generated using methanethiol-nitrogen calibration mixtures in Tedlar gas-sampling bags (SKC Inc., Eighty Four, PA). Mean values from three independent trials are reported with error bars representing the standard error of the means.

$35 \mathrm{~S}$ and $3 \mathrm{H}$ studies 
In $3 \mathrm{H}$ and $35 \mathrm{~S}$ studies, cultures of " $\mathrm{F}$. acidarmanus" were grown heterotrophically in 50 $\mathrm{ml}$ NoS containing $350 \mathrm{mM} \mathrm{Na} 2 \mathrm{SO} 4$ and harvested by centrifugation $(10 \mathrm{~min}, 12,200 \cdot \mathrm{g}$ at $21 \mathrm{C}$ ) following 7 days of incubation. The cell pellet was resuspended in $5 \mathrm{ml}$ of NoS medium with either $150 \mathrm{lCi}$ of $3 \mathrm{H}$-methionine, 35S-methionine, 35S-cysteine, or $1 \mathrm{mCi}$ $\mathrm{Na} 2$ 35SO4 (ICN Biomedicals, Irvine, CA) and incubated for $4 \mathrm{~h}$ at $37 \mathrm{C}$. Then, $5 \mathrm{ml}$ of the initial culture supernatant was added and incubated for $20 \mathrm{~h}$. The remaining supernatant was added to a final volume of $50 \mathrm{ml}$, and incubated for 56 days at $37 \mathrm{C}$. The headspace gas was directed into zinc-acetate traps, and since "F. acidarmanus" is microaerophilic (Baumler et al. 2005), $60 \mathrm{cc}$ of air was injected every 3.5 days into the culture flask which forced headspace gases into the zinc-acetate trap. The precipitate was collected and resuspended in a liquid scintillation vial with $5 \mathrm{ml}$ Instagel (Packard Instruments, Meriden, CT) and analyzed with a LS 6500 multi-purpose scintillation counter (Beckman Coulter, Fullerton, CA).

\section{Cell lysates}

The cell lysates for enzyme assays were prepared from $400 \mathrm{ml}$ of a 14-day " $\mathrm{F}$. acidarmanus" culture grown in mfer and harvested by centrifugation (12,200.g, $10 \mathrm{~min}$ at $21 \mathrm{C}$ ). The supernatant was discarded and the cell pellets were resuspended in $3.0 \mathrm{ml}$ of $1 \%(\mathrm{w} / \mathrm{v}) \mathrm{NaCl}$ acidified to $\mathrm{pH} 1.0$ with $\mathrm{H} 2 \mathrm{SO} 4$. The resuspended cell mixture was transferred to two $1.5 \mathrm{ml}$ microcentrifuge tubes and centrifuged $(12,200 \cdot \mathrm{g}$ for $10 \mathrm{~min}$ at 21 C) and the supernatants discarded. Next, the surface of the cell pellets were gently washed with $750 \mathrm{ll} \mathrm{dH} 2 \mathrm{O}$ to remove any residual traces of $\mathrm{pH} 1.0$ solution. One of the cell pellets was resuspended in 75011 of $0.2 \mathrm{M} \mathrm{Na} 2 \mathrm{HPO} 4$ which was then used to resuspend the second cell pellet. The cell suspension was transferred to a $15 \mathrm{ml}$ conical tube, and 21311 of $0.2 \mathrm{M} \mathrm{Na} 2 \mathrm{HPO} 4$ and $1.5 \mathrm{ml} \mathrm{dH} 2 \mathrm{O}$ were added and vortexed for $15 \mathrm{~s}$. Next, 30011 of $0.1 \mathrm{M}$ citric acid and $237 \mathrm{ll} \mathrm{dH} 2 \mathrm{O}$ were added. The final crude lysate (3 $\mathrm{ml})$ had a $\mathrm{pH}$ of 6.2. For assays conducted at $\mathrm{pH} 6.8,6.5$, or 5.5, citric acid (0.1 M) and $\mathrm{dH} 2 \mathrm{O}$ were added at the following volumes 120 and 417 11, 220 and 317 11, or 440 and 97 11, respectively. Cell lysis occurred as the membrane lipids of "F. acidarmanus" dissociate at neutral $\mathrm{pH}$. Lysis efficiency was determined at this step by enumerating the viable cells/ml using the MPN procedure $(\mathrm{n}=3)$, and compared to MPN's taken following the first resuspension step $[3.0 \mathrm{ml}$ of $1 \%(\mathrm{w} / \mathrm{v}) \mathrm{NaCl}$ acidified to $\mathrm{pH} 1.0$ with $\mathrm{H} 2 \mathrm{SO} 4]$. Lysis efficiency was determined and indicated that less than 103 viable cells remained of the $* 1010$ cells used. Protein concentrations of the crude lysates were determined using the BCA protein assay kit (Pierce, Rockford, IL) with BSA used as standard.

Sulfite reductase activity

The lysate $(3 \mathrm{ml})$ was placed into $10 \mathrm{ml}$-headspace vials (Wheaton) and EDTA (1mM), DTT (5 mM), and Na2SO3 (25 mM) added. Finally, 105.211 citrate phosphate buffer (CPB) was added to the reaction mixture ( $\mathrm{pH} 6.2$, final volume of $3.2 \mathrm{ml}$ ). Vials were flushed with nitrogen gas, and crimp-sealed with PTFE-silicone headspace seals (Wheaton). The vial was incubated at $37 \mathrm{C}$ and the reaction started by injecting NADPH 
to a final concentration of $100 \mathrm{lM}$. At each timepoint, $250 \mathrm{ll}$ of headspace was sampled and the amount of MT monitored using GCPFPD. Mean values from five independent trials are reported with error bars representing the standard error of the means.

S-adenosylmethionine-dependent thiol methyltransferase activity

Cell extracts $(0.5 \mathrm{ml})$ were assayed for thiol methyl transferase (TMT) activity using a radiometric assay that measures the transfer of the $3 \mathrm{H}$-methyl group from [methyl-3H]Sadenosyl-L-methionine (SAM) to sulfide as described by Drotar et al. (1987). The reaction was started by addition of $0.1 \mathrm{mM}$ [methyl-3H]SAM and incubation at $37 \mathrm{C}$ for 30 or $60 \mathrm{~min}$. The reaction was terminated by addition of $0.25 \mathrm{ml} \mathrm{NaOH}(10 \mathrm{M})$. Toluene (Sigma) was added $(6 \mathrm{ml})$ to the reaction mixture and the tube was mixed by inversion ten times, and $4.5 \mathrm{ml}$ of the organic layer was added to $5 \mathrm{ml}$ of instagel and analyzed by LSC. Three trials of the assay were performed and the data are presented as the mean values \pm the standard error of the mean.

\section{Methionine-c-lyase activity}

Cell lysates were prepared as described above, with the exception that the $\mathrm{pH}$ was adjusted to 6.8 instead of 6.2. The final reaction mixture contained $0.2 \mathrm{mM}$ pyridoxal 50phosphate hydrate (PLP) and either $5 \mathrm{mM}$ L-methionine (Sigma) or $5 \mathrm{mM} \mathrm{L}$-cysteine hydrochloride monohydrate (Sigma) in a final volume of $1.0 \mathrm{ml}$. The reaction mixture was placed in $2 \mathrm{ml} \mathrm{GC}$ headspace vials (National Scientific Co., Rockwood, TN), sealed, and the reaction started by incubation at 37 C. Mean values from three independent trials are reported with error bars representing the standard error of the mean.

\section{Results}

Headspace gases of "F. acidarmanus" cultures were analyzed for sulfur gases by GC/MS using the selective ion monitoring mode for the detection of VSCs [H2S, SO2, (CH3)2S, (CH3)2S2, CH3SH, CS2, or COS]. The headspace from chemolithotrophically grown "F. acidarmanus" (7 or 14 day cultures) contained MT (CH3SH) and some DMDS [(CH3)2S2] with elution times of 3.9 and 8.9 min, respectively (Fig. 1). MT and DMDS were also detected in "F. acidarmanus" cultures grown heterotrophically (7 or 14 days) in either NoS with $350 \mathrm{mM} \mathrm{Na} 2 \mathrm{SO} 4$ or in mfer (FeSO4 replaced with $100 \mathrm{mM} \mathrm{MgSO} 4$ ). The low levels of DMDS in the samples were most likely due to the conversion of MT to DMDS in the presence of oxygen (Lomans et al. 2002; Nordmann et al. 1994). In the headspace of sealed "F. acidarmanus" cultures (14 days), O2 levels decreased, CO2 levels increased, and $\mathrm{N} 2, \mathrm{CH} 4$, and $\mathrm{H} 2$ remained unchanged compared to cell-free controls sealed for 14 days (data not shown).

Since some sulfate-reducing prokaryotes can degrade methionine with the release of MT (Kiene and Visscher 1987; Taylor and Kiene 1987) and in order to compare the production of VSC in " $F$. acidarmanus" with a bona fide sulfate-reducing prokaryote, the headspace gases of Archaeoglobus fulgidus, a well-characterized sulfatereducing archaeon, was examined. In the headspace gases of A. fulgidus, $\mathrm{H} 2 \mathrm{~S}$ and some $\mathrm{SO} 2$ were 
detected but not MT or DMDS (data not shown). Pilcher et al. (2003) reported that MT can be formed by the transfer of methyl groups from the organic constituents of the culture medium to sulfides such as H2S (Visscher and van Gemerden 1993; Visscher et al. 2003). To address this possibility, a 1.0 M NaS solution was injected into a sealed headspace vial containing uninoculated mfer as a control. GC/MS analysis revealed the presence of $\mathrm{H} 2 \mathrm{~S}$ and $\mathrm{SO} 2$ but no MT or DMDS (data not shown). Thus, the presence of MT in the headspace gas of " $F$. acidarmanus" cultures was a result of microbial metabolism and not abiotic reactions among medium constituents and sulfide ions.

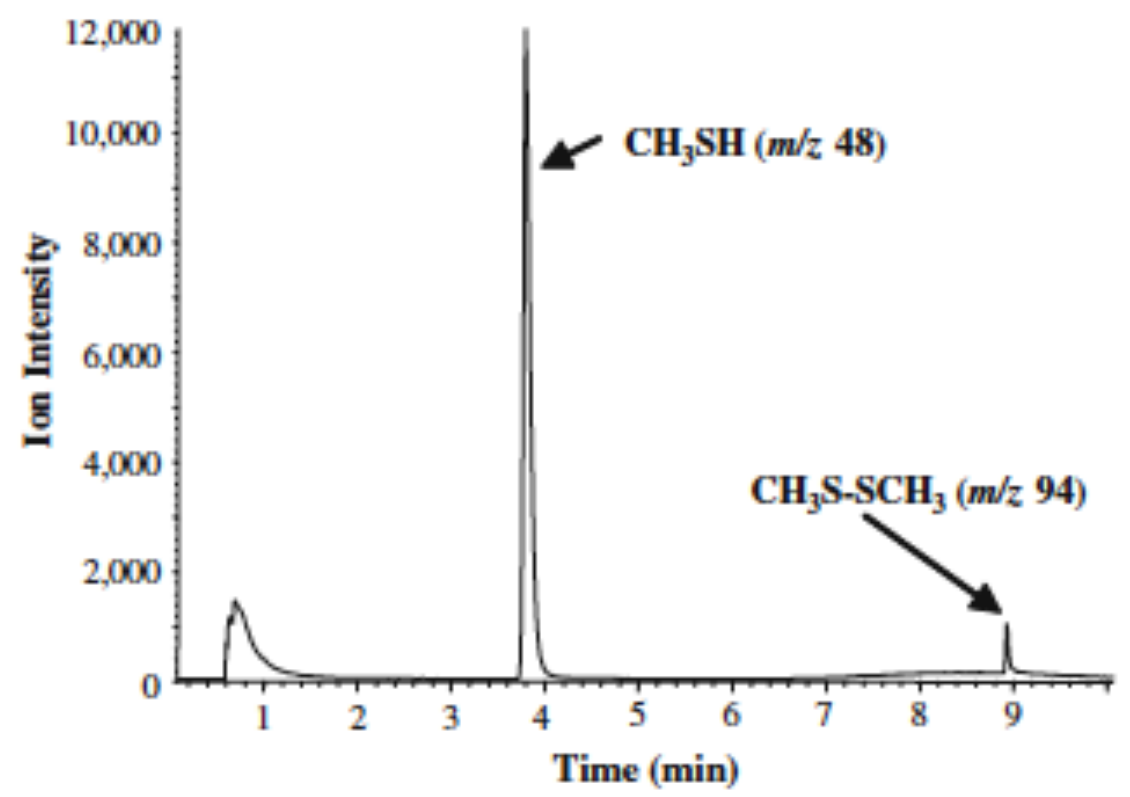

Fig. 1 Volatile organic sulfur compounds detected in the headspace of "F. acidarmanus" cultures using GC/MS. The profile shows peaks for methanethiol $(\mathrm{m} / \mathrm{z} 48)$ and dimethyldisulfide ( $\mathrm{m} / \mathrm{z}$ 94)

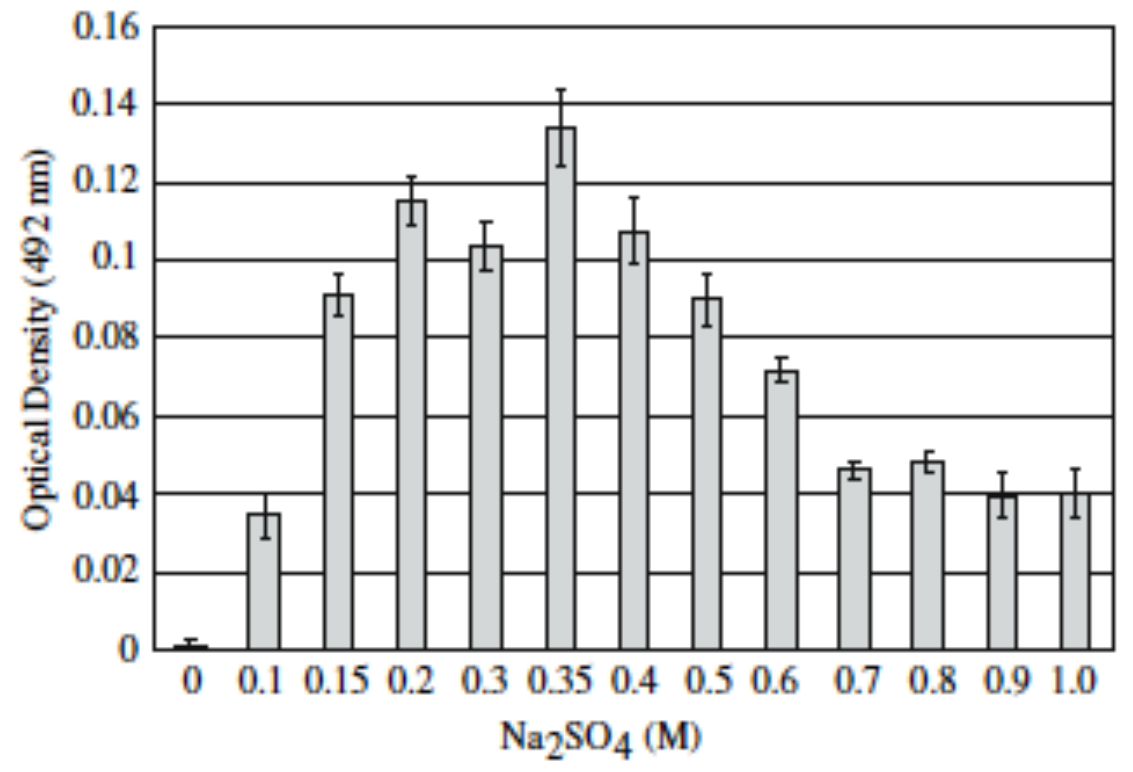


Fig. 2 Sulfate-dependent growth of "F. acidarmanus", The optimal concentration of $\mathrm{Na} 2 \mathrm{SO} 4$ for growth was determined spectrophotometrically using $\mathrm{HCl}$-acidified NoS ( $\mathrm{pH}$ 1.0) medium supplemented with concentrations of $\mathrm{Na} 2 \mathrm{SO} 4$ ranging from 0 to $1 \mathrm{M}$ and incubation for 14 days at 37 C. Background absorbance of uninoculated NoS medium was subtracted from optical density values. All data represent the mean from three trials. Error bars represent the standard error of the mean

As a precursor to experiments with 35S-labeled substrates and to control for the level of SO4 2-in the medium, the growth of "F. acidarmanus" at different sulfate concentrations was evaluated in $\mathrm{NoS}$ medium with $\mathrm{Na} 2 \mathrm{SO} 4$ added as the sole sulfate source. After 14 days of incubation, growth (OD492[0.05) was detected in the range of 150-600 mM Na2SO4. The highest cell density was achieved at $350 \mathrm{mM}$ (Fig. 2). The growth of " $\mathrm{F}$. acidarmanus" in NoS medium with sulfate added as $\mathrm{MgSO} 4$, resulted in a similar trend with growth occurring between 150 and $500 \mathrm{mM}$ and the greatest optical density obtained at $500 \mathrm{mM}$ (data not shown). To test if the absence of growth at[700 mM Na2SO4 or [500 mM MgSO4 was due to toxic levels of the cationic group or SO4 2-, growth studies in NoS medium containing an equimolar mixture of $\mathrm{Na} 2 \mathrm{SO} 4$ and $\mathrm{MgSO} 4$ were added in the range of 0-1.0 M SO4. " $\mathrm{F}$. acidarmanus" growth (OD492[0.05) occurred at SO4 2- concentrations up to and including $1 \mathrm{M}$, indicating that $\mathrm{SO} 4$ did not inhibit growth at this level. Inhibitory concentrations of $\mathrm{Na}+$ and $\mathrm{Mg} 2+$ were $1.2 \mathrm{M}$ and $500 \mathrm{mM}$, respectively. A concentration of $350 \mathrm{mM} \mathrm{SO} 42-$ was used in subsequent studies with NoS medium.

To determine if the production of MT was associated with a particular phase of growth or whether it is a constitutive process, viability and MT production during chemolithotrophic and heterotrophic growth of "F. acidarmanus" were monitored. Chemolithotrophic and heterotrophic cultures produced MT during both log and stationary phases of growth with the greatest level of production occurring at day 8 and 12, respectively (Fig. 3). The quantities of MT decreased slightly or remained steady for 4 days after reaching maximum levels and declined thereafter. Cultures grown in the presence of FeSO4 (chemolithotrophic) produced MT more rapidly and at greater quantities than heterotrophic cultures. These findings indicated that MT production is constitutive and linked with active cell metabolism.

MT is typically produced by microbes that metabolize the sulfur-containing amino acids methionine and cysteine (Bentley and Chasteen 2004). The growth media for " $F$. acidarmanus" contain some methionine and cysteine in the added yeast extract as well as SO4 2-. To identify the sulfur source(s) used for MT production, 35S-labelled amino acids were utilized. Headspace gases from cultures grown in NoS supplemented with 35S-methionine or 35S-cysteine were directed into zinc acetate traps that resulted in the formation of a white metallothiol precipitate. Following the addition of radiolabeled substrate, 7 days of incubation were necessary before precipitates were visible in the zinc acetate traps. The harvested precipitate contained $35 \mathrm{~S}$ activity with the greatest level present 21 days after the addition of either labeled amino acid. The level of precipitate and $35 \mathrm{~S}$ present decreased during the next 35 days of incubation (Fig. 4a, b). The quantity of $35 \mathrm{~S}$ recovered from methionine was approximately six times greater than that 
with cysteine when maximum recoveries (day 21) were compared. These data showed that both methionine and cysteine could serve as precursors to the production of MT but production from methionine metabolism was significantly greater.

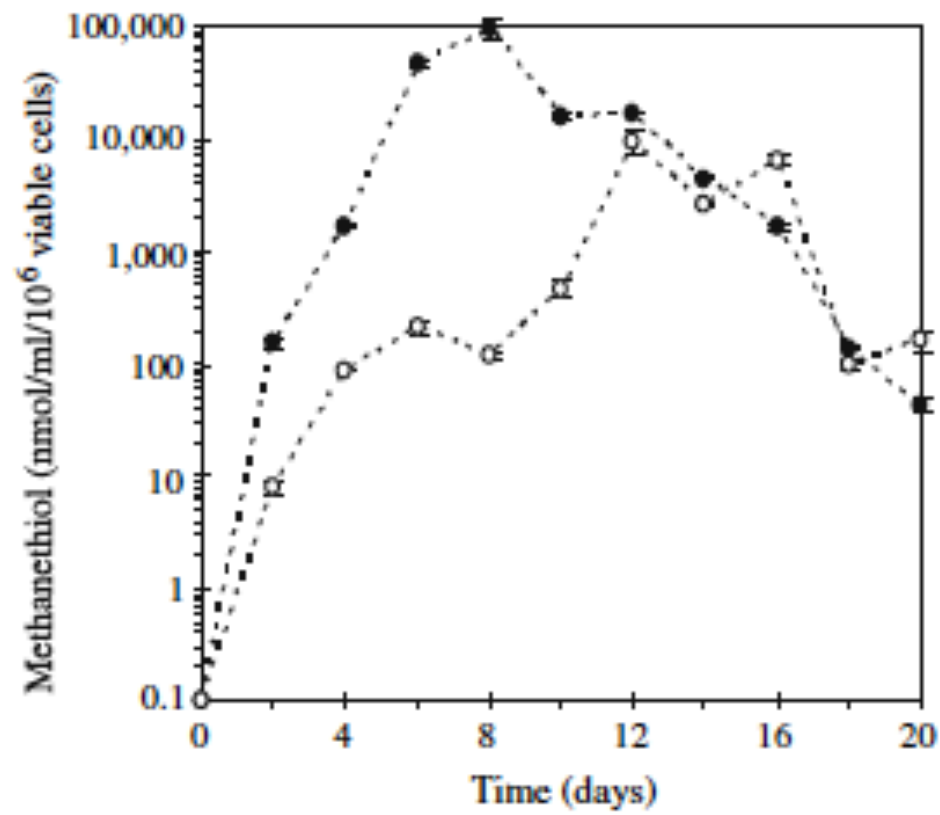

Fig. 3 Methanethiol production during growth of "F. acidarmanus". Cells were grown chemolithotrophically (filled circle) or heterotrophically (open circle) in sealed headspace vials and incubated for 20 days at 37 C. At the indicated timepoints, the concentration of methanethiol was determined by GC/PFPD and viable cells enumerated by a most probable number method. The data are mean values from three independent trials. Error bars represent the standard error of the mean

The terminal methyl group of methionine can be cleaved as a methyl-thiol group (SCH3) or function as a substrate for methyl transfer (Bentley and Chasteen 2004). Therefore, studies with $3 \mathrm{H}$-methionine were conducted to determine if " $\mathrm{F}$. acidarmanus" cleaves or utilizes the terminal methyl group of methionine in the production of MT. 3H-activity was detected in the harvested metallothiol precipitate in zinc acetate traps throughout the 56-day experiment (Fig. 4c); however, the maximum amount of activity was recovered at day 35,2 weeks after the peak recovery with $35 \mathrm{~S}$-methionine. These results demonstrated that the methyl group of methionine contributes to the formation of MT by "F. acidarmanus" but probably by a different pathway from that used by the sulfur of methionine. 

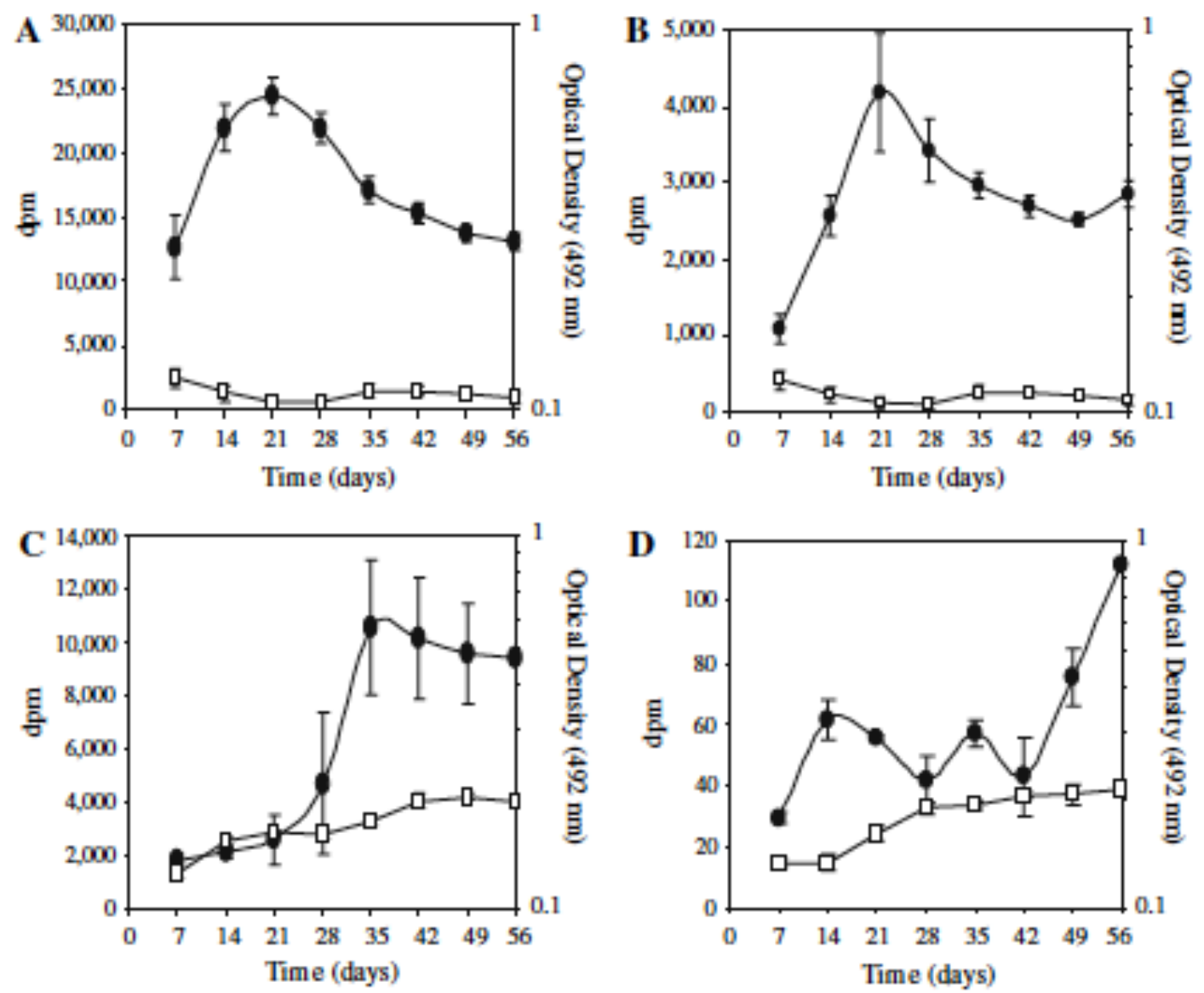

Fig. 4 Utilization of methionine, cysteine, and sulfate in methanethiol production. Logphase cells were resuspended in NoS medium supplemented with either 150 1Ci 35Smethionine (a), $150 \mathrm{lCi} 35 \mathrm{Scysteine} \mathrm{(b),} 150 \mathrm{lCi}$ [methyl-3H]methionine (c), or $1 \mathrm{mCi}$ of $\mathrm{Na} 235 \mathrm{SO} 4$ (d) and incubated for $4 \mathrm{~h}$ at $37 \mathrm{C}$. After incubation, $5 \mathrm{ml}$ of supernatant from the original culture was added and the culture incubated for an additional $20 \mathrm{~h}$. The remaining supernatant from the original culture medium was then added ( $50 \mathrm{ml}$ final volume) and incubated for 56 days at 37 C. The headspace gas was directed into a zincacetate trap $(10 \% \mathrm{w} / \mathrm{v})$. Sixty cubic centimeter of air was injected every 3.5 days into the culture headspace to sustain " $\mathrm{F}$. acidarmanus" growth. The metallothiol precipitate was collected and resuspended in $5 \mathrm{ml}$ instagel and analyzed by LSC (filled circle).

Background counts from cultures with no radiolabeled substrate added were subtracted from the data presented. The optical densities of cultures are also shown (open square)

Initial experiments with cultures pulsed in NoS medium supplemented with 150 1Ci Na2 $35 \mathrm{SO} 4$ and $350 \mathrm{mM}$ Na2SO 4 revealed no radioactive activity (above background) in the harvested metallothiol precipitate throughout the 56-day study. Based on the background radiation and on the concentrations of non-radiolabeled SO4 2-, the level of detection for $35 \mathrm{SO} 42$ - required that the ratio of labeled:unlabeled sulfate to be approximately 1:5 . 107. The ratio in our initial experiment was $* 1: 1 \cdot 108$. To determine if the negative results from our initial 35SO4 2- experiment was a result of the detection limit, an attempt was made to 
improve the labeled:unlabeled sulfate ratio by lowering the amount of $\mathrm{Na} 2 \mathrm{SO} 4$ in the NoS medium to 100 lM. However, "F. acidarmanus" cells did not survive at this level of sulfate [MPN assay revealed a [108 decrease in viable cells (data not shown)]. Consequently, a third attempt was undertaken where the amount of 35SO4 2 - was increase from $150 \mathrm{lCi}$ to $1 \mathrm{mCi}$, which provided a labeled:unlabeled ratio of $1: 2 \cdot 107$. In this experiment, a low level of radioactivity was detected in the metallothiol precipitates after corrections for background, indicating that " $\mathrm{F}$. acidarmanus" was capable of using sulfate to produce MT (Fig. 4d).

At the end of experiments with radiolabeled substrate, TCA-insoluble material was collected and tested for the presence of $35 \mathrm{~S}$ or $3 \mathrm{H}$. The detection of radioactivity in TCA-insoluble cellular components coupled with its removal by proteinase $\mathrm{K}$ treatment demonstrated that $35 \mathrm{~S}$-methionine, $3 \mathrm{H}$-methionine, and 35S-cysteine were incorporated into protein. In most cases, the proteinase $\mathrm{K}$ treatment removed over $50 \%$ of the total radioactivity from the TCA-insoluble fraction (Table 1). Experiments with $35 \mathrm{SO} 42$ - indicated that some sulfate was assimilated into protein, most likely through the production pathways for cysteine and methionine.

MT can be produced via cleavage of the methyl-thiol (-SCH3) group of methionine by methionine-c-lyase (MGL) (Tokoro et al. 2003). When "F. acidarmanus" lysates ( $\mathrm{pH} \mathrm{6.8)}$ were incubated with $0.2 \mathrm{mM}$ pyridoxal 50-phosphate (PLP) and 5 $\mathrm{mM}$ L-methionine, increasing amounts of MT were detected with time throughout the $90 \mathrm{~min}$ incubation (Fig. 5). When $5 \mathrm{mM} \mathrm{L}$-cysteine was added to cell lysates with $0.2 \mathrm{mM}$ PLP instead of methionine, H2S (data not shown) was detected in addition to a significant ( $\mathrm{P} \backslash 0.0001)$ amount of MT compared to either lysates without Lcysteine or to boiled cell preparations (Fig. 5). Control cell lysates with $0.2 \mathrm{mM}$ PLP but no added methionine or cysteine produced a low level of MT that increased with incubation time. This likely represented the degradation of endogenous methionine and cysteine present in cell lysates. The amount produced was significantly less than the reactions with added L-methionine or L-cysteine. Boiled lysates containing 5 $\mathrm{mM}$ of either L-methionine or L-cysteine produced negligible amounts of MT (Fig. 5). Overall, these results indicated that "F. acidarmanus" lysates possessed MGL-like activity (Tokoro et al. 2003). The formation of MT from cysteine may proceed by the cleavage of HS- followed by methylation involving a thiol methyltransferase (TMT). 


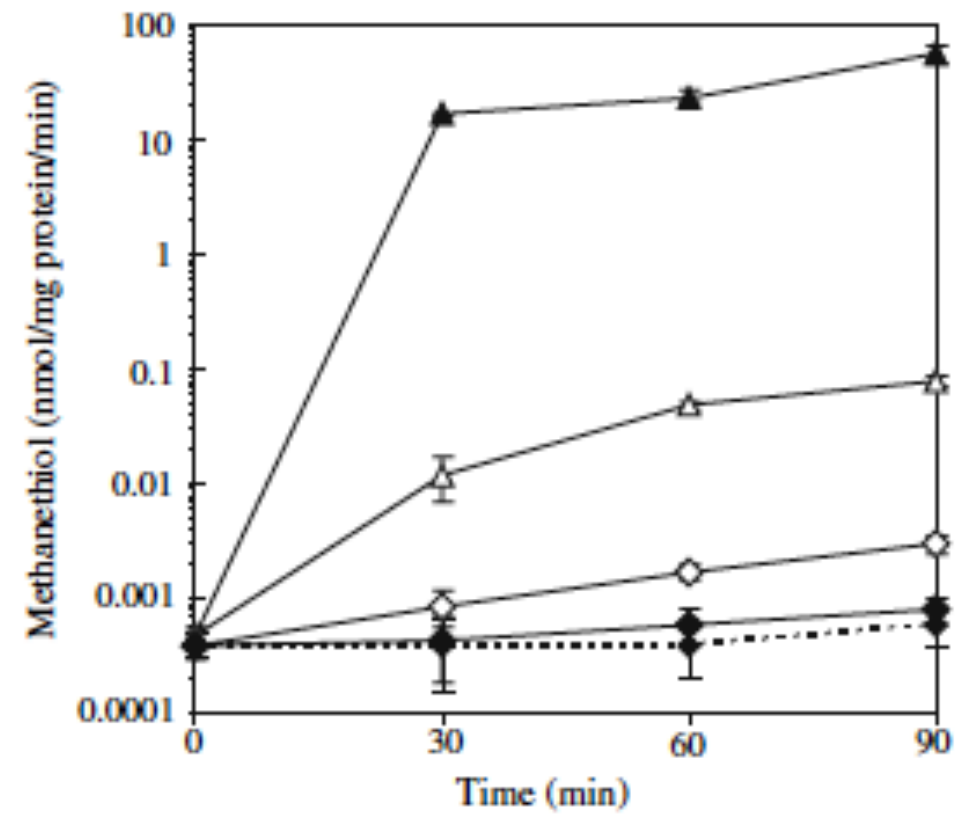

Fig. 5 Methanethiol production from methionine and cysteine by cell lysates. The cell lysates were prepared as previously described. Reaction mixtures were comprised of 1.0 $\mathrm{ml}$ of citrate phosphate buffer ( $\mathrm{pH} 6.8), 0.02 \mathrm{mM}$ pyridoxal 50-phosphate hydrate, and 5 $\mathrm{mM}$ of either methionine (filled triangle) or cysteine (open triangle). The reaction mixtures were incubated at $37 \mathrm{C}$ and headspace samples (250 11) analyzed by GC/PFPD every $30 \mathrm{~min}$. Boiled cell lysates containing $5 \mathrm{mM}$ of methionine (filled diamond) or cysteine (filled diamond in dotted line) and lysates incubated without methionine or cysteine (open diamond) served as controls. The data points are mean values from three independent trials. Error bars represent the standard error of the mean

Since the 35SO4 2- experiments indicated that sulfate was used to produce MT and incorporated into protein, most likely by the assimilatory sulfate reduction pathway, a cell lysate assay was developed to test for the presence of sulfite reductase activity. Cell lysates were incubated in headspace vials under nitrogen at $37 \quad \mathrm{C}$ and samples analyzed every $30 \mathrm{~min}$ by GC/PFPD. Elution times for H2S, MT, and DMDS were 1.8, 4.2, and $6.2 \mathrm{~min}$, respectively. Under the cell lysate assay conditions, H2S was not detected when lysates were incubated with SO3 2-, but rather MT was produced (Fig. 6). One possible explanation is that enzymes for both reduction of SO3 2- to HS- and subsequent methylation to MT were present and active in the cell lysates. Further evidence to support the existence of a sulfite reductase was the requirement for NADPH. No MT was detected when lysates were incubated with alternative electron donors such as NADH or thioredoxin, or when lysates were incubated without SO3 2-. MT was not detected with boiled cell extracts, which indicated that the production of MT was not the result of nonenzymatic side reactions with SO3 2-. These results provided evidence for a NADPHdependent sulfite reductase activity and TMT activity in cell lysates of " $\mathrm{F}$. acidarmanus." 


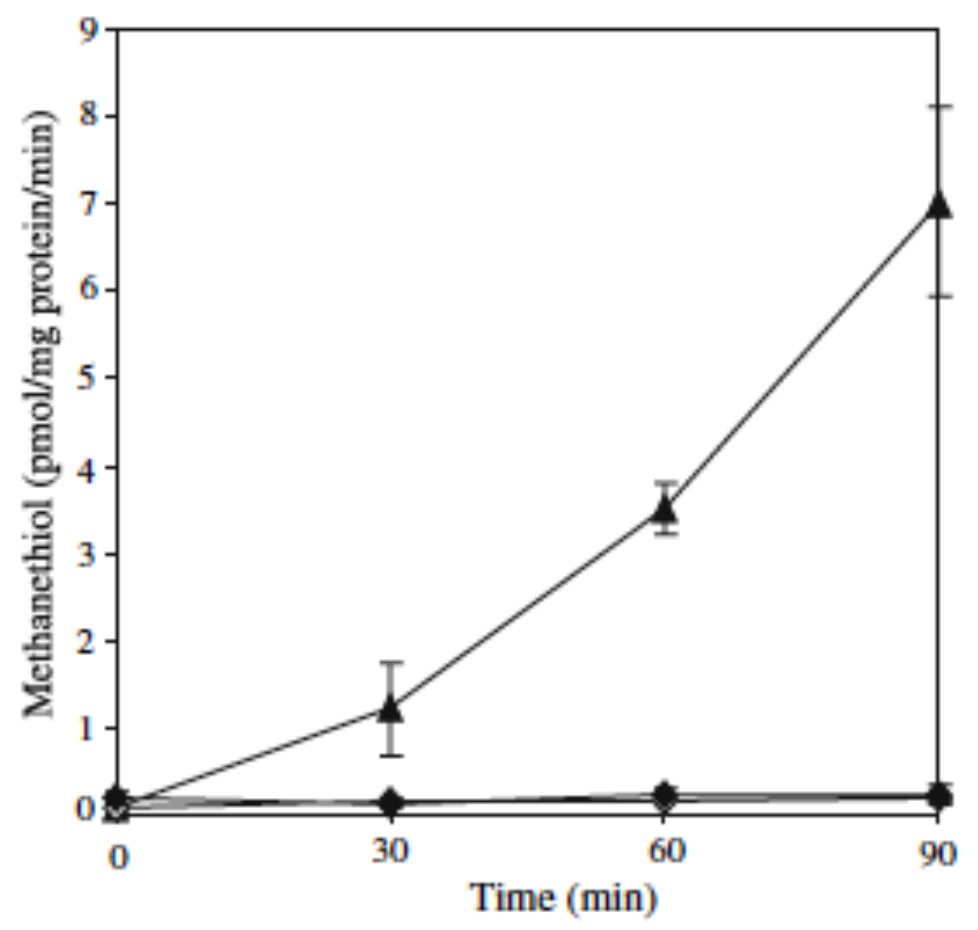

Fig. 6 Methanethiol production from sulfite by cell lysates. The cell lysates were transferred to a nitrogen-flushed vial and sealed with a teflon-coated septum cap. Standard reactions were performed in $3.2 \mathrm{ml}$ citrate phosphate buffer, $\mathrm{pH} \mathrm{6.2,} \mathrm{and}$ containing $1.0 \mathrm{mM}$ EDTA and 5.0 mM DTT. NADPH (100 lM) and Na2SO3 (25 mM) were added to the lysates (filled triangle) and incubated at $37 \mathrm{C}$ and headspace samples (250 11) analyzed by GC/PFPD every $30 \mathrm{~min}$. Boiled (15 min) cell lysates (filled diamond) and lysates incubated without sodium sulfate (open diamond) served as controls. The data presented are the mean values from five independent trials. Error bars represent the standard error of the mean

The results with whole cells demonstrating the utilization of the terminal methyl group of $3 \mathrm{H}$-methionine in MT formation as well as the production of MT from SO3 2- by cell lysates indicated the possible presence of a TMT. However, tests for the presence of a SAM-dependent methyltransferase in cell lysates adjusted to $\mathrm{pH} 6.5$ by a radiometric method (Drotar et al. 1987) did not detect significant activity. Similar results were obtained with lysates adjusted to $\mathrm{pH} 5.5$ (data not shown). It is possible that the enzymatic assay conditions were not optimal or an alternative methyl donor is used.

\section{Discussion}

Due to the absence of genetic methods and the difficulty associated with the propagation of many extremophilic archaea, this study utilized a biochemical approach to address the following objectives pertaining to sulfur metabolism in " $\mathrm{F}$. acidarmanus": (1) identify the VSC present in headspace gases, (2) discern precursors to VSC production, (3) develop and utilize an assay for detection of enzyme activities, and (4) begin to elucidate the significance of sulfur compounds in 
the physiology of this unique archaeon. Results from this study determined that " $\mathrm{F}$. acidarmanus" constitutively produce the VOSC MT and is the first report of such activity in an acidophilic archaeon. Considering the sulfate requirements and the abundance of sulfate and other sulfur-containing compounds in the habitats occupied by this organism, it is likely that the production of MT and sulfur metabolism are central to its physiology.

The development and use of NoS medium where SO4 2- was added as Na2SO4 or $\mathrm{MgSO} 4$ permitted the determination of SO4 2- quantities necessary for growth and survival. Growth occurred in the SO4 2 - range of $150 \mathrm{mM}$ to $1 \mathrm{M}$, and $\$ 1 \mathrm{mM}$ was required for survival (data not shown). The high level of sulfate required for optimal growth and survival of "F. acidarmanus" is unique. Previously, we reported that heterotrophic growth required the addition of $100 \mathrm{mM}$ of a SO4 2 - containing salt to mfer medium (Baumler et al. 2005). mfer contains SO4 $2-$ in the basal salts and the acidulate (H2SO4) which amounts to $96 \mathrm{mM}$ plus either FeSO4 $(72 \mathrm{mM})$ or a SO4 $2-$ containing salt $(100 \mathrm{mM})$ that results in a final SO4 2 - concentration of $168 \mathrm{mM}$ and $196 \mathrm{mM}$, respectively. These values are within the range of sulfate concentrations that resulted in " $\mathrm{F}$. acidarmanus" growth in the current study. The optimal growth concentration of $350 \mathrm{mM} \mathrm{SO} 42-$ is the highest reported for a prokaryote. The Richmond mine, where isolation of " $\mathrm{F}$. acidarmanus" occurred, was reported to have SO4 2- concentrations that fluctuated between 657 and $786 \mathrm{mM}$ when monitored through 1999-2002 (Druschel et al. 2004 ). Therefore, growth in the range of $150 \mathrm{mM}$ to $1 \mathrm{MSO} 42-$ is not surprising. In comparison, sulfate-reducing prokaryotes from freshwater and marine environments grow optimally at sulfate levels of 100-250 I M and around $25 \mathrm{mM}$, respectively (Nealson 1997 ). The importance of sulfate and sulfur compounds metabolism in acidophiles occupying ecological niches high in sulfate may have been over-looked in the past due to the difficulties associate with detecting isotopic tracers when ambient levels of sulfate are high.

The incorporation of 35 SO4 2 - into proteins indicated that " $\mathbf{F}$. acidarmanus " imports sulfate and carries out assimilatory sulfate reduction. Additionally, once the ratio of hot:cold sulfate particles was adjusted for detection limits, 35 SO4 2- was found in metallothiol precipitates from headspace gases of cultures fed with radiolabeled sulfate. Further, cell lysate assays found MT after the addition of sulfite. The absence of PLP in this assay eliminated the possibility of MT production by methionine-c -lyase (MGL) where MT is produced from the cleavage of methionine because PLP is a required cofactor for MGL. Thus, it appears that " $\mathbf{F}$. acidarmanus "' is capable of producing MT via at least two different pathways.

The production of MT by the methylation of sulfide, including sulfide that was produced as a result of the reduction of sulfate, has been proposed (Drotar et al. 1987 ; Soda et al. 1983 ; Bak et al. 1992 ; Grech-Mora et al. 1996 ; Lomans et al. 2001). However, the activity of the most common class of thiol methyltransferase, the SAMdependent methyltransferase, was no detected in the assay conditions employed in this study. This may mean that either the methylation of sulfide is 
mediated by a methyltransferase that does not utilize SAM, or that the SAMdependent methyltransferase in " $\mathbf{F}$. acidarmanus " has a different characteristic than those previously reported.

While both L -methionine and L -cysteine are used to produce MT in " $\mathbf{F}$. acidarmanus ," they are not utilized in identical fashions. After 21 days of incubation with the radiolabeled amino acids, when peak production of MT was detected, cultures fed with $35 \mathrm{~S}$-methionine produced approximately six times more activity in $35 \mathrm{~S}$-containing metallothiol precipitates than cultures fed with $35 \mathrm{~S}$ cysteine. These results may reflect a greater uptake of methionine, a preference for cysteine incorporation into protein, or enzyme specificity (i.e., MGL). Alternatively, the amount of methionine and cysteine present in yeast extract (not determined) may affect the rate of MT production from $35 \mathrm{~S}$-labeled methionine or cysteine. In comparison, the peak activity in the precipitate from cultures fed with $3 \mathrm{H}$ methionine (3 H-methyl group of methionine) occurred at day 35 rather day 21 as noted with the $35 \mathrm{~S}$-labeled amino acids. This suggested that the methyl group of methionine was incorporated into MT by a pathway other than directly from methionine and involving a carbon-sulfur lyase (i.e., MGL). It is possible that methylase activity that uses methionine as a methyl donor shunts the labeled methyl group to other cellular constituents until they are degraded to release MT; however, it is currently unclear what pathway might be involved or why the peak activity with $3 \mathrm{H}$-methionine occurs 2 weeks after the maximum activity noted with 35 S-methionine.

In cell lysate assays supplemented with the cofactor PLP and either L -methionine or L -cysteine, MT alone or H2 S and MT were produced, respectively. These findings indicated that the cell lysate contains MGL-like activity. The binding site for PLP (prosite PD0C00677) was used to identify candidate ORFs for the enzymes in the transulfuration pathway in the genome of " $\mathbf{F}$. acidarmanus " (cystathionine-c lyase, cystathionine-c -synthase, cystathionine- b -lyase, and MGL). Only two PLPbinding candidates for cystathionine-c -synthase (GenBank Accession Number ZP_00609085 and ZP_00610186) were identified. In the work of Tokoro et al. (2003), only two PLP binding candidates in Entamoeba histolytica were found. When these loci were cloned and the enzymes characterized, both were found to function as MGLs. Phylogenetic analysis of these two loci suggested a horizontal gene transfer event from an archaeon. The activity indicative of MGL in " $\mathbf{F}$. acidarmanus " warrants further investigation to determine the precise functions of the two PLP-binding protein candidates.

Examinations of the complete genome of "F . acidarmanus " also shed light on other aspects of sulfate metabolism. The typical assimilatory sulfate reduction pathway consists of three key enzymes: the sulfate adenylyltransferas (EC: 2.7.7.4), the 30 -phosphoadenosine 50 -phosphoadenosine (PAPS) reductase (EC: 1.8.4.8), and the assimilatory sulfite reductase (EC: 1.8.1.2). The annotated genome of " $\mathbf{F}$. 
acidarmanus " contains a putative match for the first enzyme (GenBank Accession Number ZP_00609637). Another locus has been annotated as the APS/PAPS reductase (GenBank Accession Number ZP_00609636), with the conserved motif (KRT)ECG(LI)H and the catalytically active cysteine residue typical of this enzyme present (Berendt et al. 1995 ; Weber et al. 2000 ). This predicted enzyme also contains two conserved cysteine pairs. This characteristic has been used in some cases to distinguish between the assimilatory versus the dissimilatory sulfate reduction pathway (Kopriva et al. 2002 ). The significance of these cysteine pairs in this predicted 'F . acidarmanus", enzyme is still unclear and its true nature remains a subject for further investigation. The third enzyme, responsible for the key step of the six-electron reduction of sulfite to sulfide, is sulfite reductase (Odom and Peck 1984 ). Despite the characterization of sulfite reductase from multiple bacteria and two archaea (Dahl et al. 1993 ; Hatchikian and Zeikus 1983 ; Lee and Peck 1971 ; Lee et al. 1973 ; Trudinger 1970 ; Johnson and Mukhopadhyay 2005), a candidate for this enzyme was not found in the " $\mathbf{F}$. acidarmanus " annotated genome. Since experimental evidence incontrovertibly indicated the presence of an enzyme that can carry out this function, the absence of a candidate gene in the annotated genome suggested that the function of this enzyme is carried out by another enzyme that is heretofore unconnected with sulfate reduction. Whatever the identity of this enzyme is, data suggested that its function is dependent on the cofactor NADPH. The identification and characterization of this enzyme should prove invaluable to the understanding of both the sulfur metabolism in general as well as its role in this acidophile.

Collectively, the results from this study provide evidence for multiple MT pathways in "F . acidarmanus" (Fig. 7 ). The significance of MT production is underscored in a study of the Lower Kane Cave in Wyoming, where the association of VOSC and the acidic cave biotope was established (Engel et al. 2004 ). The findings from our studies have identified a new contributor to the global cycling of sulfur. This is the first report of an acidophilic MT-producing archaeon. The constitutive production of MT by " $\mathbf{F}$. acidarmanus " provides new insight into acidic communities since the production of MT may function in a general detoxification system and/or serve as substrate or a chemotactic signal to associated members of the acidic community (Edwards et al. 2000 ; Tyson et al. 2005 ; Baker et al. 2003 ; Baker et al. 2004 ). The uptake from the $\mathrm{pH} 1.0$ growth medium and incorporation of $35 \mathrm{~S}$ methionine and $35 \mathrm{~S}$-cysteine into protein has broader implications since it establishes a protein-labeling method for application in studies to identify proteins induced in response to changes in the environment or nutrients (Macario et al. 1999). 


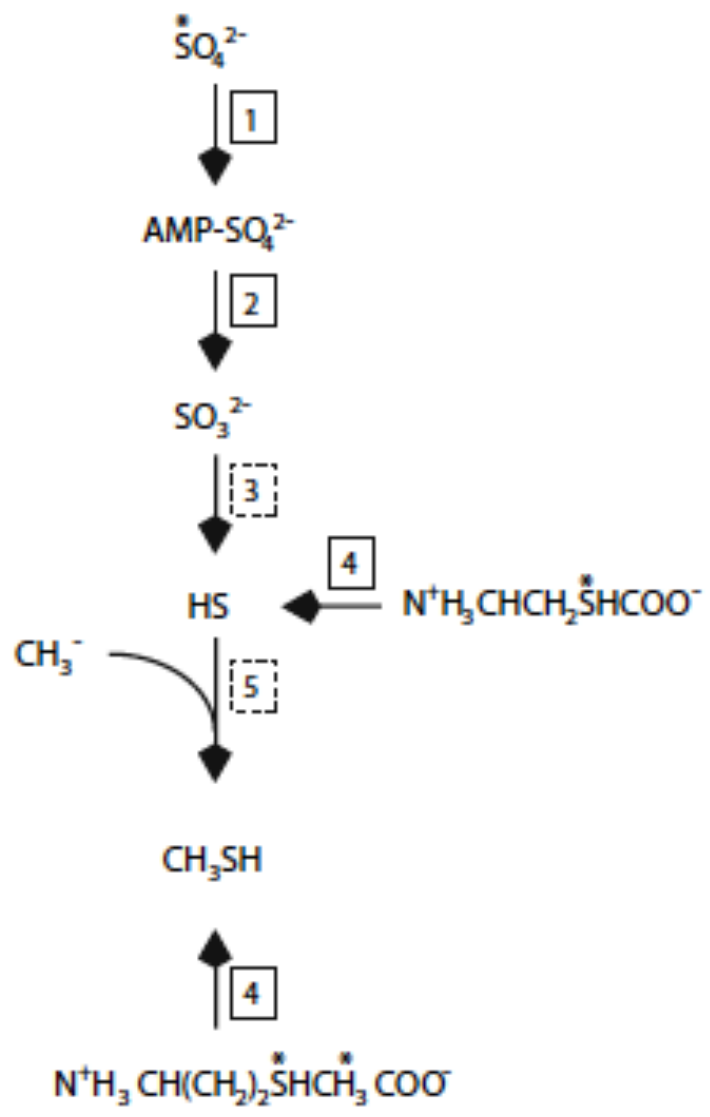

Fig. 7 Proposed pathways of methanethiol production by "F. acidarmanus". 1 sulfate adenylyltransferase, $\mathbf{2}$ adenosine 50-phosphosulfate reductase, $\mathbf{3}$ sulfite reductase, $\mathbf{4}$ methionine-c-lyase, $\mathbf{5}$ thiol S-methyltransferase. Solid boxes represent annotated open reading frames of the genome. Dashed-line boxes represent enzymes with no significant sequence similarity identified in the genome. Asterisks represent labeled substrates used in experiments

Likewise, the generation of cell extracts suitable for use in enzyme assays should facilitate elucidation of the metabolism of other related genera that also have a completed genome sequence through genome annotation and protein identification and characterization. The in vitro production of MT from sulfite suggests the presence of a sulfite reductase that likely produces sulfide that is methylated to form MT; however, additional work is required to identify and isolate candidate enzymes. Considering the optimal level of sulfate required for growth and survival of " $\mathbf{F}$. acidarmanus ", it is likely that future studies will provide new insights into the fundamental role of sulfur in the physiology of acidophiles as well as their contributions to the global sulfur cycle and acidic biotopes.

Acknowledgments We thank Dr. Yeonhwa Park, Jayne Storkson, Karen Albright, Wei Liu, Dr. Mike W. Pariza (Department of Food Microbiology and Toxicology, University of Wisconsin-Madison), and Lea McMartin, Brad Pierce, and Dr. Brian G. Fox (Department of Biochemistry, University of Wisconsin-Madison) for assistance with GC/MS studies. This work was supported by the Michael and Winona Foster Wisconsin 
Distinguished Graduate Fellowship (D.J.B) and in part by NSF-LexEn Grant MCB9978205, and the University of Wisconsin-Madison, College of Agricultural and Life Sciences.

\section{References}

Allen EE, Tyson GW, Whitaker RJ, Detter JC, Richardson PM, Banfield JF (2007) Genome dynamics in a natural archaeal population. Proc Natl Acad Sci 104:1883-1888

Bak F, Finster K, Rothfuß F (1992) Formation of dimethylsulfide and methanethiol from methoxylated aromatic compounds and inorganic sulfide by newly isolated anaerobic bacteria. Arch Microbiol 157:529-534

Baker BJ, Hugenholtz P, Dawson SC, Banfield JF (2003) Extremely acidophilic protests from acid mine drainage host Rickettsialeslineage endosymbionts that have intervening sequences in their 16S rRNA genes. Appl Environ Microbiol 69:5512-5518

Baker BJ, Lutz MA, Dawson SC, Bond PL, Banfield JF (2004) Metabolically active eukaryotic communities in extremely acidic mine drainage. Appl Environ Microbiol 70:6264-6271

Baumler DJ, Jeong KC, Fox BG, Banfield JF, Kaspar CW (2005) Sulfate requirement for heterotrophic growth of "Ferroplasma acidarmanus" strain fer1. Res Microbiol 156:492-498

Bentley R, Chasteen TG (2004) Environmental VOSCs-formation and degradation of dimethyl sulfide, methanethiol, and related materials. Chemosphere 55:291-317

Berendt U, Haverkamp T, Prior A, Schwenn JD (1995) Reaction mechanism of thioredoxin: 30-phospho-adenylylsulfate reductase investigated by site-directed mutagenesis. Eur J Biochem $233: 347-356$

Cline JD (1969) Spectrophotometric determination of hydrogen sulfide in natural waters. Limnol Oceanol 14:454-458

Dahl C, Kredich NM, Deutzmann R, Trüper HG (1993) Dissimilatory sulphite reductase from Archaeoglobus fulgidus:

physicochemical properties of the enzyme and cloning, sequencing and analysis of the reductase genes. J Gen Microbiol 139:1817-1828 
Drotar A, Burton GA, Tavernier JE, Fall R (1987) Widespread occurrence of bacterial thiol methyltransferases and the biogenic emission of methylated sulfur gases. Appl Environ Microbiol 53:1626-1631

Druschel GK, Baker BJ, Gihring TM, Banfield JF (2004) Acid mine drainage biogeochemistry at Iron Mountain, California. Geochem Trans 5:13-32

Edwards KJ, Bond PL, Gihring TM, Banfield JF (2000) An archaeal iron-oxidizing extreme acidophile important in acid mine drainage. Science 287:1796-1799

Engel AS, Porter ML, Stern LA, Quinlan S, Bennett PC (2004) Bacterial diversity and ecosystem function of filamentous microbial mats from aphotic (cave) sulfidic springs dominated by chemolithoautotrophic "Epsilonproteo bacteria". FEMS Microbiol Ecol 51:31-53

Ferrer M, Golyshina OV, Beloqui A, Golyshin PN, Timmis KN (2007) The cellular machinery of Ferroplasma acidiphilum is iron-protein-dominated. Nature 445:91-94

Giovannoni SJ, Stingl U (2005) Molecular diversity and ecology of microbial plankton. Nature 427:343-348

Grech-Mora I, Fardeau M-L, Patel BKC, Ollivier B, Rimbault A, Prensier G, Garcia J-L, Garnier-Sillam E (1996) Isolation and characterization of Sporobacter termitidis gen. nov., sp. nov., from the digestive tract of the wood-feeding termite Nasutitermes lujae. Int J Syst Bacteriol 46:512-518

Hatchikian EC, Zeikus JG (1983) Characterization of a new type of dissimilatory sulfite reductase present in Thermodesulfobacterium commune. J Bacteriol 153:1211-1220

Johnson EF, Mukhopadhyay B (2005) A new type of sulfite reductase, a novel coenzyme F420-dependent enzyme, from the methanarchaeon Methanocaldococcus jannaschii. J Biol Chem 280:38776-38786

Kelly DP, Wood AP, Jordan SL, Padden AN, Gorlenko VM, Dubinina GA (1994) Biological production and consumption of gaseous organic sulphur compounds. Biochem Soc Trans 22:1011-1015 
Kiene RP (1996) Production of methanethiol from dimethylsulfoniopropionate in marine surface waters. Mar Chem 54:69-83

Kiene RP, Visscher PT (1987) Production and fate of methylated sulfur compounds from methionine and simethylsulfoniopropoinate in anoxic salt marsh sediment. Appl Environ Microbiol $53: 2426-2434$

Kopriva S, Büchert T, Fritz G, Suter M, Benda R, Schünemann V, Koprivova A, Schuermann P, Trautwein AX, Kroneck PMH, Brunold C (2002) The presence of an iron-sulfur cluster in adenosine 50-phosphosulfate reductase separates organisms utilizing adenosine 50-phosphosulfate and phosphoadenosine 50phosphosulfate for sulfate assimilation. J Biol Chem 277:2178621791

Lee J-P, Peck HD Jr (1971) Purification of the enzyme reducing bisulfite to trithionate from Desulfovibrio gigas and its identification as desulfoviridin. Biochem Biophys Res Commun 45:583-589

Lee J-P, Yi C-S, LeGall J, Peck HD Jr (1973) Isolation of a new pigment, desulforubidin, from Desulfovibrio desulfuricans (Norway strain) and its role in sulfite reduction. J Bacteriol 115:453455

Lomans BP, Leijdekkers P, Wesselink J-J, Bakkes P, Pol A, van der Drift C, Op den Camp HJM (2001) Obligate sulfide-dependent degradation of methoxylated aromatic compounds and formation of methanethiol and dimethyl sulfide by a freshwater sediment isolate, Parasporobacterium paucivorans gen. nov., sp. nov. Appl Environ Microbiol 67:4017-4023

Lomans BP, van der Drift C, Pol A, Op den Camp HJ (2002) Microbial cycling of volatile organic sulfur compounds. Cell Mol Life Sci 59:575-588

Macalady JL, Vestling MM, Baumler DJ, Boekelheide N, Kaspar CW, Banfield JF (2004) Tetraether-linked membrane monolayers in Ferroplasma spp: a key to survival in acid. Extremophiles $8: 411-419$

Macario AJL, Lange M, Ahring BK, De Macario EC (1999) Stress genes and proteins in the archaea. Microbiol Mol Biol Rev 63:923-967 
Nealson KH (1997) Sediment bacteria: who's there, what are they doing, and what's new? Annu Rev Earth Planet Sci 25:403-434 Nordmann B, Lebert MR, Alam M, Nitz S, Kollmannsberger H, Oesterhelt D, Hazelbauer GL (1994) Identification of volatile forms of methyl groups released by Halobacterium salinarium. $\mathrm{J}$ Biol Chem 269:16449-16454

Nordstrom DK, Alpers CN (1999) Negative pH, efflorescent mineralogy, and consequences for environmental restoration at the Iron Mountain Superfund site, California. Proc Natl Acad Sci 96:3455-3462

Odom JM, Peck HDJr (1984) Hydrogenase, electron transfer proteins, and energy coupling in the sulfate-reducing bacteria Desulfovibrio. Annu Rev Microbiol 38:551-592

Pilcher CB (2003) Biosignatures of early Earth. Astrobiology 3:471486

Soda K, Tanaka H, Esaki N (1983) Multifunctional biocatalysis: methionine c-lyase. Trends Biochem Sci 8:214-217

Taylor BF, Kiene RP (1987) Microbial metabolism of dimethyl sulfide. In: Saltzman ES, Cooper WJ (eds) American chemical society symposium series 393: biogenic sulfur in the environment. American Chemical Society, Washington D.C, pp 202-221

Tokoro M, Asai T, Kobayashi S, Takeuchi T, Nozaki T (2003) Identification and characterization of two isoenzymes of methionine c-lyase. J Biol Chem 278:42717-42727

Trudinger PA (1970) Carbon monoxide-reacting pigment from Desulfotomaculum nigrificans and its possible relevance to sulfite reduction. J Bacteriol 104:158-170

Tyson GW, Lo I, Baker BJ, Allen EE, Hugenholtz P, Banfield JF (2005) Genome-directed isolation of the key nitrogen fixer Leptospirillum ferrodiazotrophum sp. nov. from an acidophilic microbial community. Appl Environ Microbiol 71:6319-6324

Visscher PT, van Gemerden H (1993) Sulfur cycling in laminated marine microbial ecosystems. In: Biogeochemistry of global change, 10th international symposium on environmental biogeochemistry. Chapman and Hall, New York, pp 672-690

Visscher PT, Baumgartner LK, Buckley DH, Rogers DR, Hogan ME, 
Raleigh CD, Turk KA, Des Marais DJ (2003) Dimethylsulfide and methanethiol formation in microbial mats: potential pathways for biogenic signatures. Environ Microbiol 5:296-308

Weber M, Suter M, Brunold C, Kopriva S (2000) Sulfate assimilation in higher plants characterization of a stable intermediate in the adenosine 50-phosphosulfate reductase. Eur J Biochem 267:3647-3653 